\title{
Hot Topics and Fronts of E-commerce teaching Research: A Scientometric Analysis in CiteSpace
}

\author{
Zong-Wei LI \\ Management school \\ Shanghai University of Engineering Science \\ Shanghai, China \\ lzw0118@163.com
}

\author{
Ming-Yan WANG \\ Management school \\ Shanghai University of Engineering Science \\ Shanghai, China
}

\begin{abstract}
By drawing a network of co-words of e-commerce teaching from WOS of 2006-2015 by bibliometrics visualization software named CiteSpace, we have detected the research hot topics of international e-commerce teaching which include ecommerce, higher education, enterprise reform, Internet and elearning. At the same time, we have detected that system design, bilingual teaching, information infrastructure are the stronger research fronts of e-commerce teaching; The emerging research front is about $\mathrm{O2O}$, cloud computing and virtual theater.
\end{abstract}

Keywords-e-commerce teaching ; bibliometrics; CiteSpace

\section{INTRODUCTION}

While rapidly developing, e-Commerce is a comprehensive, multidiscipline area. In recent years, E-Commerce teaching has attracted much attention in the field of education. Thus, it is important to explore the hot spots and the leading edge of the e-Commerce teaching research to guide education theory and practice and to further deepen the reform of education.

Co-word analysis is an important method in bibliometrics based on counting and analyzing the co-occurrences of words (Callon et al. 1991). Developed by Chen (2004) from Drexel University, CiteSpace is a useful tool to visualize patterns and analyze trends of scientific literatures (Chen, 2006) .

This paper applied CiteSpace III to analyze the development and research trends of e-commerce teaching research. We discussed co-occurrences references from two aspects in CiteSpace, cluster aspect and timeline aspect, and studied from the perspective of time and space.

\section{DATA AND METHODOLOGY}

\section{A. Data collection}

In order to study the latest trends and changes of Ecommerce teaching research, we collected the literature data between 2006 and 2015 from the Web of Science (WOS) Core Collection database provided by American Institute for Scientific Information (ISI) on November 6, 2015. Under the mode of topic, we used "E-commerce" or "E-business" as first topic and a "teaching" or "education" or "course" as second topic, and obtained 337 records. The contents such as title, author, abstract and references of each bibliographic record will be put into the CiteSpace III(Version3.8).

\section{B. Analysis procedure}

The steps of CiteSpace analysis were as follows:

Import the data into CiteSpace, set time slicing option (1 years per slice), and defined timeline (from 2006 to 2015). Term Source consisted of Title, Abstract, Descriptors and Identifiers. The links we set cosine strength and the scope within slices. We selected Top 50 most or occurred items for each slice.

\section{RESULTS}

According to the retrieval results of Web of Science, we obtained the publications about E-commerce teaching research per year in Web of Science during 2006-2015. As shown in "Fig. 1,".

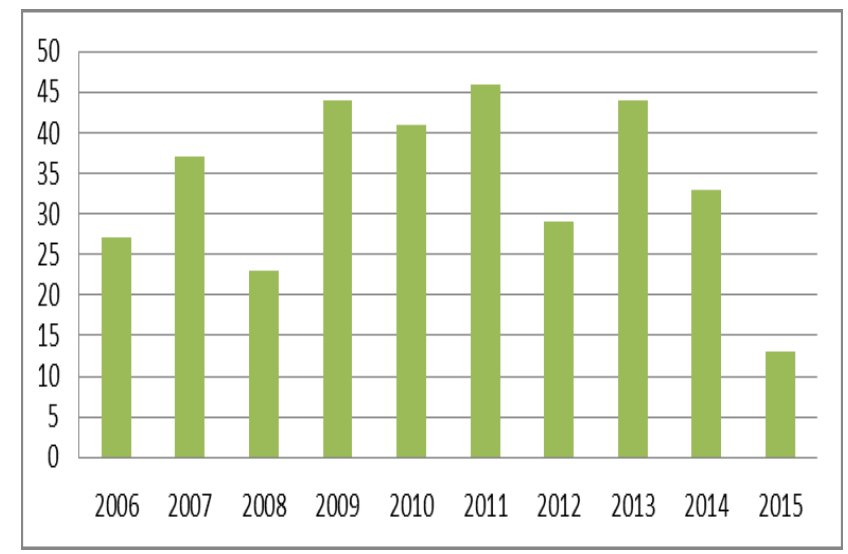

Fig. 1. The number of publications per year,2006-2015

The publications of E-commerce teaching research had shown a range from 20 to 50 over the past decade. Owing to the time we collected papers didn't cover the whole month of 2015, the data in 2015 seemed increase of the number of the literatures.

\section{A. Co-words analysis in CiteSpace.}

We observe keywords in publications about E-commerce teaching. In order to further discover keywords, we exported the top 20 records from all 761 records sorted by frequency in our database - the highest to the lowest (see Table 1).

Project of Core course with e-commerce sponsored by Shanghai Municipal Education Commission（s201503003）. 
TABLE I. TABLE TOP 20 KEYWORDS OF THE REFERENCES OF PAPERS RANKED BY FREQUENCY

\begin{tabular}{cccccc}
\hline Freq & keyword & $\begin{array}{c}\text { \% of } \\
\mathbf{7 6 1}\end{array}$ & Freq & keyword & \%of761 \\
\hline $\begin{array}{c}\text { e-commerce } \\
\text { education } \\
\text { (higher }\end{array}$ & 145 & $19.1 \%$ & Teaching & 6 & $0.8 \%$ \\
education) & 24 & $3.2 \%$ & Technology & 6 & $0.8 \%$ \\
e-learning & 18 & $2.4 \%$ & entrepreneurship & 6 & $0.8 \%$ \\
internet & 14 & $1.8 \%$ & teaching reform & 6 & $0.8 \%$ \\
management & 8 & $1.1 \%$ & Evaluation & 5 & $0.7 \%$ \\
$\begin{array}{c}\text { model } \\
\text { trust } \\
\text { digital }\end{array}$ & 8 & $1.1 \%$ & Adoption & 5 & $0.7 \%$ \\
divide & 7 & $0.9 \%$ & Behavior & 5 & $0.7 \%$ \\
$\begin{array}{c}\text { active } \\
\text { learning }\end{array}$ & 6 & $0.9 \%$ & Acceptance & 5 & $0.7 \%$ \\
innovation & 6 & $0.8 \%$ & cloud & 5 & $0.7 \%$ \\
\hline
\end{tabular}

Note: Some keywords referred to the same thing (such as e-commerce, e-business, electronic commerce) but the program cannot recognize this anomaly, so we merged them manually.

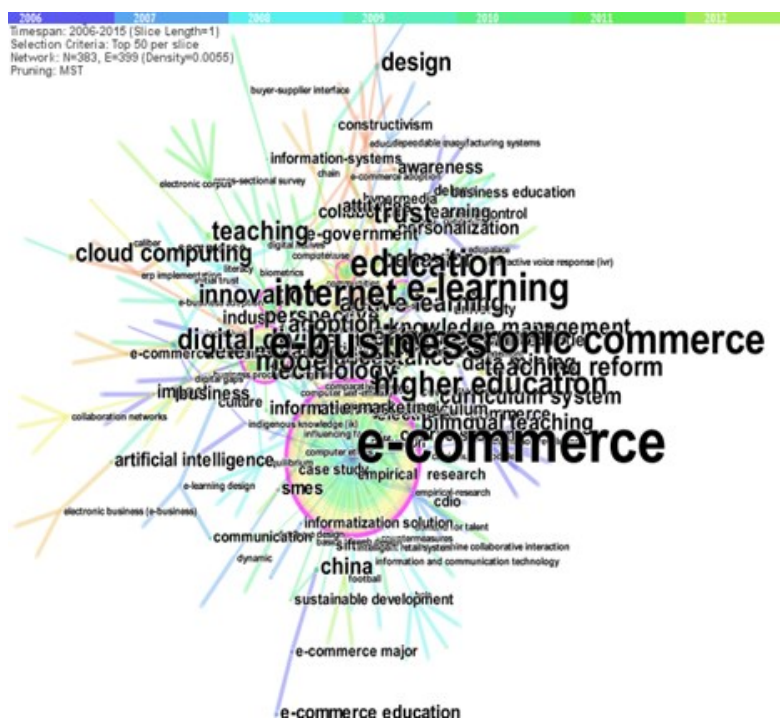

Fig. 2. A network of co-words of e-commerce teaching papers(20062015,one year slices

As shown in "Fig. 2," the network was generated based on original co-occurrence. It could intuitively reflect the relationships among high frequency keywords. The relative size of nodes was proportional to the occurrence frequencies, and the relative size of lines represents the correlation degree between keywords. Nodes of "e-commerce", "higher education", "enterprise reform", "Internet" and "e-learning", had the relatively bigger size, indicating they had the relatively higher frequency of occurrence. Also, the thicker lines between two nodes, such as "e-commerce" and "higher education", "e-business" and "enterprise reform", "course system' and "teaching reform', represented their stronger connections.

\section{B. Timeline mode of Co-words analysis clusters}

We did a further analysis from the perspective of timeline visualization about how the network was divided into distinct co-occurrence clusters in "Fig. 3,".

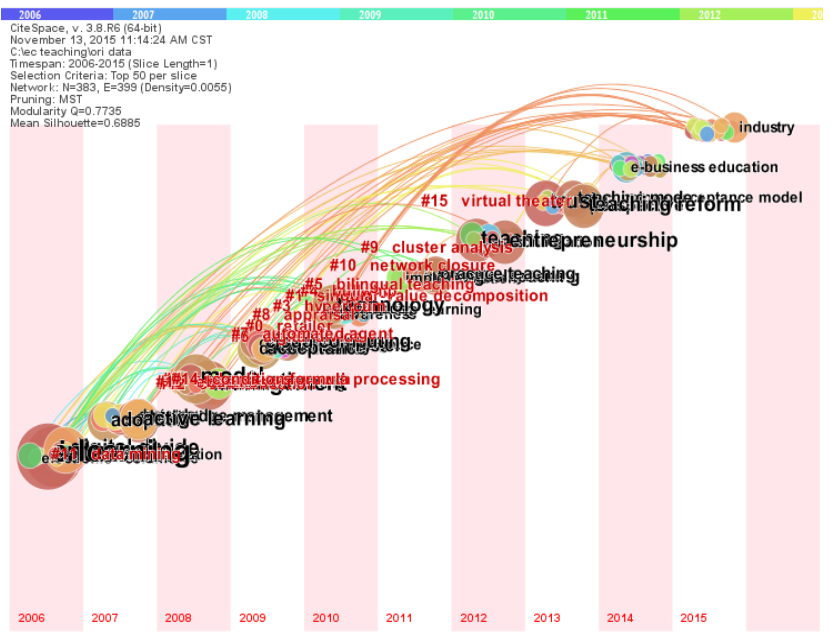

Fig. 3. Map of timeline mode of keywords

According to figure 3 , we found three points in the past decades: from 2006 to 2008 researchers paid attention to technique and policy, mainly appeared for the cluster \#11"data mining", cluster \#14 "condition formula processing" and cluster \#12 "communication", research literature such as "data mining techniques and applications study" of Lavrac, N (2006) and" Data mining in higher education" of Schonbrunn, K. \& Hilbert, A(2007) emerged, some literature discussed the topic of "system design" or "database design", such as " Enhancing student learning in database courses with large data sets" (Gudivada et al. 2007); The research from 2009 to 2012 focused "on teaching reform"(cluster\#5),"cluster analysis"(cluster \#9) and "problem based learning"(cluster \#4), the typical papers included "The Teaching Reform of Ecommerce Security Course"(Min, X. S.2010), "Study on Teaching Reform of E-commerce with the Mode of Combining Research and Teaching Based on Propriate Teaching Materials"(Meng et al.,2011); From 2013 to 2015,the research hot spots were "virtual theater"(cluster \#15), "industry"."A Virtual Campus for E-learning Inclusion: The Case of SVCG9 " (Perez-Gonzalez et al.,2014) was the most representative article for this cluster. Xiao put forward high-level Ecommerce applied talents cultivating mode from the perspective of whole industrial chain(2015) .Some keywords emerged, such as "o2o"," Cloud Computing", the representative papers were "Providing Services for Student Relationship Management on Cloud Computing Infrastructure"(Radenkovic et al.2013) and "Application of $\mathrm{O} 2 \mathrm{O}$ in Information-Based Teaching”(Zhang, L. L.,Jia, X. W.) .

\section{CONCLUSION AND LIMITATION}

In this study, we used CiteSpace III to implement a study of the research trends and development of E-commerce teaching, and deepen our understanding of this field. We detected the research trends and development of E-commerce teaching, observed that new technique and teaching reform still the hottest direction of the this area. Thanks to Internet, big data, and a series of new generation technology, industry-academy linkage and virtual theater have called attention of the Ecommerce course. 
Inevitably, there were limitations to this paper. Firstly, because the keywords we chose to generate the data base could not cover the all the situation, our results might not be universal. Secondly, the data collected in this study only cover the recent one decade, more information before this time were neglected.

\section{REFERENCES}

[1] Callon,M.,Courtial,J.,Turner,W.,\&Bauin,S...'Fromtranslationstoproblem aticnetworks:An wordanalysis". SocialScienceInformation,22(2),191, 1983.

[2] Chen, C. "Searching for intellectual turning points: Progressive Knowledge Domain Visualization". Proc. Nat. Acad. Sci., 101(Suppl.):5303-5310, 2004

[3] Chen, C. "CiteSpace II: Detecting and visualizing emerging trends and transient patterns in scientific literature". Journal of the American Society for Information Science and Technology, 57(3), 2006, 359-377.

[4] Lavrac, N. "SolEuNet: Selected data mining techniques and applications". From Data and Information Analysis to Knowledge Engineering, 2006,32-39.

[5] Schonbrunn, K.Hilbert, A." Data mining in higher education. Advances in Data Analysis", Advances in Data Analysis ,2007,489-496.
[6] Gudivada, V. N.Nandigam, J.Tao, Y. L. .'Enhancing student learning in database courses with large data sets". 37th Annual Frontiers in Education Conference, Global Engineering : Knowledge without Borders - Opportunities without Passports, Vols 1- 4, 1343-1347,2007.

[7] Min, X. S.. "The Teaching Reform of E-commerce Security Course." National Teaching Seminar on Cryptography and Information Security, 205-207,2010.

[8] Meng, H. Y.Tian, Q. M.Zhang, D. J. "Study on Teaching Reform of Ecommerce with the Mode of Combining Research and Teaching Based on Propriate Teaching Materials". Advances in Computer Science, Environment, Ecoinformatics, and Education, Pt 5,218(303-308),2011.

[9] Perez-Gonzalez, D.Soto-Acosta, P.Popa, S." A Virtual Campus for Elearning Inclusion: The Case of SVC-G9". Journal of Universal Computer Science, vol. 20, pp. 240-253, 2014.

[10] Xiao, J. H.Luo, S. Y. "High-Level E-Commerce Applied Talents Cultivation From the Perspective of Whole Industrial Chain". International Conference on Modern Education and Social Science (Mess 2015). 327-331.

[11] Radenkovic, B.Despotovic-Zrakic, M.Bogdanovic, Z.Labus, A.Milutinovic, M.. "Providing Services for Student Relationship Management on Cloud Computing Infrastructure". 2013 11th International Conference on Telecommunication in Modern Satellite, Cable and Broadcasting Services. New York :385-388, 2013.

[12] Zhang, L. L.Jia, X. W.. "Application of O2O in Information-Based Teaching." International Symposium Modern Education and Human Sciences (Mehs 2014): 661-664 